\title{
XII.
}

\section{Ueber eine eigenthümliche, vielleicht syphilitische Enteritis.}

\author{
Von Prof. C. J. Eberth in Zürich.
}

Aus dem hiesigen Entbindungshaus wurde mir im Januar d. J. ein angeblich syphilitisches Kind äbergeben, das von einer 21jährigen, anscheinend gesunden, Erstgebärenden nach circa 24stündiger normaler Geburtsarbeit geboren wurde. Der Vater des Kindes war unbekannt.

Die Eiläute und Placenta boten nichts Abnormes, dagegen zeigte das Kind eine Reihe von Veränderungen, die mit grosser Wahrscheinlichkeit einen syphilitischen Ursprung vermuthen liessen.

Das Resultat der etwa 24 Stunden nach der Geburt vorgenommenen Section ist Folgendes.

Gewicht des Kindes $2 \frac{6}{8}$ Pfund: Länge 40 Centimeter. Kopfmaasse $1^{12}, 2^{9}$, $3^{4}, 3^{10}$, Umfang 27 Centimeter. Alter circa $30-32$ Wochen.

Die Epidermis an einzelnen Stellen leicht macerirt; an der Planta und der inneren Seite der Füsse, zwischen den Zehen, sowie an der Vola manus und zwischen den Fingern ist die Epidermis durch dünnflüssigen gut aussehenden Eiter zu hirsekorn- bis erbsengrossen Blasen abgehoben.

Das Unterhautgewebe der Kopfschwarte besonders über dem linken Seitenwandbein in grösserer Ausdehnung blutig serös infiltrirt. Die ziemlich stark injicirte Pia mit Blut durchtränkt. Die Sinus sehr blutreich. Die weisse Hirnsubstanz rosig injicirt, die graue Rinde im Allgemeinen blass.

Die fast wallnussgrosse sehr derbe und blutreiche Thymus von mehreren linsen- bis bohnengrossen Abscessen durchsetzt, die einen dickflüssigen Eiter enthalten, der durch einen leichten Wasserstrahl sich entfernen lässt. Daneben ungefăhr gleich grosse, trockene Stellen von käsigem Aussehen, die bald in der Gestalt circumscripter Knoten gegen das übrige Parenchym sich absetzen, bald mehr diffuse Infiltrationen desselben bilden.

Die Lungenpleura beiderseits an einzelnen Punkten mit einem trocknen dünnen Faserstoffbelag bedeckt, der sich besonders über mehreren erbsen- bis bohnengrossen, graugelben, über die Umgebung leicht prominirenden Knoten in etwas grösserer Menge findet.

Die Lungen auf dem Durchschnitt luftleer, stellenweise glänzend und von grauröthlicher Farbe, daneben mehr diffuse, derbe, trockne hellere grauröthliche Infiltrationen und mehr gelbliche knotige Einlagerungen von Erbsen- bis Haselnussgrösse. Letztere liegen bald peripber, bald central und entsprechen zum grossen Theil den schon erwähnten oberfächlichen Knoten. Während die Peripherie dieser Massen mehr trocken und derb erscheint, ist das Centrum weich, und bietet mehr das Aussehen eines etwas dicken Eiters. 
Trachea und Herz zeigen nichts Bemerkenswerthes.

Leber normal gross und hyperämisch.

Milz um das Doppelte vergrössert, mit einer dünnen, leicht abziehbaren Faserstofflage bedeckt, Parenchym derb, dunkelroth, Malpighische Körper zablreich, nicht vergrössert, Trabekeln spärlich.

Die Nieren normal gross, Corticalis blass, Pyramidalis blutreich.

Das Peritoneum parietale und viscerale an vielen Orten durch eine dünne Faserstofflage mit einander verklebt. Einzelne Darmschlingen inniger mit reichlicberen und festeren Faserstoffmassen verlöthet. Die Wandungen derselben entsprechend diesen Verklebungen durch ringförmige, circa $\frac{3}{4}$ Centimeter breite käsige Einlagerungen von gummöser Beschaffenheit beträchtlich verdickt und das Lumen verengt. Die Darmmucosa ist $\mathrm{n}$ e ben diesen Infiltrationen, die ich an 8 verschiedenen Stellen des mittleren und unteren Dünndarms nachweisen konnte, ganz normal, weder die solitären noch die Peyer'schen Foflikel bieten irgend eine Veränderung; dagegen ist die Schleimbaut über diesen erkrankten Partien stellenweise gelockert und ulcerirt. Mitunter finden sich die gummösen Massen in unmittelbarer Nähe der normalen Peyer'schen Haufen und Solitärdrüsen, ein Verhältniss, das in Verbindung mit ibrer charakteristischen ringförmigen Gestalt jedenfalls für eine beschränkte Betheiligung des Follikelapparates an diesen Neubildungen spricht.

Die Lymphdrïsen und Nebennieren ohne besondere Veränderung. Im Grund des noch offenen Processus vaginalis beiderseits reichliche eitrig faserstoffige Massen, die als grobe Flocken und Klumpen die Serosa bedecken, obne die Theile miteinander zu verkleben.

Die mikroskopische Untersuchang ergab zunächst fïr die diffusen grauroth hepatisirten Lungenpartien eine reichliche Wucherung junger Zrllen sowohl in den Wandungen der Alveolen, wie in Interstitien der Läppchen. $\mathrm{Zu}$ dieser Wucherung gesellten sich in den gelhen knotigen Infiltrationen reicblicbe Massen theils epithelialer Formationen, theils in fettigem Zerfall begriffener junger Zellen, welche die Alveolen sehr vollständig erfïllten. In den Centren der Knoten waren durch die verbreitete Necrobiose mit Detrıtus gefüllte Hohlräume entstanden.

Sehr leicht liessen sich all diese Verbältnisse nach längerêr Conservirung in chromsaurem Kali an dïnnen Schnitten und ausgepinselten carminisirten Präparaten studiren.

Den gleirhen Charakter einer frübzeitig der fettigen Metamorphose anheim fallenden Granulationsgeschwulst boten die Gummiknoten in der Thymus und den Gedärmen. An dem letzteren Ort war besonders deutlich die gleichmässige Infiltration sämmtlicher Darmbäute ausgesprocien, so dass auch hier wie in den Lungen die Wucherung sich wesentlich auf das interstitielle Gewebe beschränkte, und kaum irgendwo, wenn nicht vielleicht in der Thymus, eine einfache Hyperplasie lymphatischer Follikel, als die primäre Erkrankung nachzuweisen war, die sich erst späterhin in die Umgebung verbreitete.

Die im Processus vaginalis befindlichen fibrinälınlichen Massen ergaben sich zusammengesetzt aus einem feinen Filz geronnenen Faserstofls mit eingelagerten Blutkörperchen und jungen Zellen. Da die Verbindung dieser Pseudomembranen 
mit der Umgebung eine ungemein lose und im Epithel der Serosa nirgends Spuren einer Zellenvermehrung zu constatiren waren, so ist es mir kaum zweifelhaft, dass die Fibringerinnsel hier nicht autochthon entstanden, sondern vielmehr aus der Bauchböhle hierhergelangt waren.

Ob nun diese gummösen Knoten in der Thymus, den Lungen und dem Darm syphilitischen Ursprungs sind oder nicht, kann bei der ungenügenden Anamnese nicht definitiv entschieden werden. Aber gewiss hat dieses anatomische Bild mit einzelnen sicher constatirten syphilitischen Veränderungen so viel Uebereinstimmendes, dass der Verdacht auf Syphilis in dem geschilderten Falle nicht ganz unmotivirt ist.

In Bezug auf die Darmaffection könnte freilich die Vergleichung nicht iiberall zutreffen, denn unter den bisher als Darmsyphilis aufgeführten Prozessen sind eine Reihe so verschiedener Formen vereinigt, dass eine Vergleichung selbst nach einer sorgfältigen Sichtung schwierig sein dürfte. Ueber die Entwickelung, die ersten Stadien der Syphilis des Digestionstractus sind unsere Kenntnisse jedenfalls noch sehr lückenhaft. Geschwüre und Stricturen sind besonders bei Erwachsenen keine grade seltenen Erscheinungen. Aber bis jetzt scheint es nur in einem Fallle*) Virchow gelungen zu sein, neben dem sich retrahirenden Geschwür die in fettiger Metamorphose begriffenen Gummistellen zu seben, aus denen die Ulceration hervorging. Auch von den syphilitischen Ulcerationen und Stricturen im Mastdarm bemerkt derselbe, dass er noch nie Gelegenheit gehabt, die ersten Stadien zu beobachten und dass er es desshalb unentschieden lasse, ob condylomatöse oder direct gummöse Anfänge das Gewöhnliche, ja ob die Geschwüre überhaupt secundärer Natur sind.

Aebnliche Affectionen wie die oben geschilderten hat Cullerier bei syphilitischen Kindern als submucöse Gummiknoten des Darmkanals beschrieben und in einem Falle congenitaler Syphilis beobachtete Förster**) , eine fibroide Entartung der Peyer'schen Drüsen mit oberflächlicher Ulceration", in einer solchen Ausdehnung, dass von den normalen Peyer'schen Haufen keine Spur mehr vorhanden war. Diese Geschwüre waren bald oval, bald

*) Geschwïlste Bd. JI. S. 415.

**) Würzburger med. Zeitschrift Bd. IV. 1863. 
gürtelförmig und ihr Grund wurde gebildet aus einem dichten Flechtwerk von Bindegewebe. Im Colon dagegen fanden sich neben geschwellten und pigmentirten' Solitärfollikeln andere mit diphtherischen Belegen, aber nirgends ausgesprochene Ulcerationen.

Der Fall, den Meschede*) jüngst von einem 36 jährigen, an constitutioneller Lues leidenden Tischlergesellen mitgetheilt hat, möchte sich vielleicht dem Vorstehenden in mancher Beziehung anreihen, obgleich darin keiner besonderen Betheiligung der Peyerschen Drüsen an den Veränderungen Erwähnung geschieht wie dort. Die im Dünndarm befindlichen zahlreichen, mitunter ringförmigen Geschwüre von $1-1 \frac{1}{2}$ Zoll Länge und $1 / 4-3 / 4$ Zoll Breite zejgten schwarz pigmentirten, granulirten Grund und strahlige Narbenbildung. Knotige Bildungen am Rande und in der Umgebung fehlten, dagegen fanden sich kleine, derbe fibröse Knötchen auf den, den Geschwüren entsprechenden Partien der Darmserosa.

Mag auch der von mir bescbriebene Fall durch die unvollständige Anamnese nur einen beschränkten Werth bieten, so gewinnt er doch durch die zahlreichen und gleichartigen, noch während des Fötallebens aufgetretenen Erkrankungsheerde in den verschiedensten Organen um so mehr ein specifisches Gepräge, als die einfach entzündlichen Erscheinungen fast ganz fehlen und, wo dieselben sich finden, als secundäre, von den älteren des Darms und der Lunge, bis in die Serosa hineinreichenden Gummiknoten ausgehend, erscheinen. Diess, aber noch mehr die geringe Kenntniss der congenitalen Darmsyphilis überhaupt mag es rechtfertigen, wenn ich einen, in der Anamnese wohl dunklen Fall in der Absicht hier verzeichne, dass er vielleicht dazu dienen könne, unsere Anschauungen, gerade über die frühesten Ștadien gewisser Syphilisformen zu ergänzen.

*) Dieses Árchiv Bd. XXXVII. 1. 565 . 